\title{
GEOTECNOLOGIAS APLICADAS AO MAPEAMENTO DA VULNERABILIDADE AMBIENTAL: ESTUDO DE CASO DO MUNICÍPIO DE RIO ACIMA/MG
}

\author{
Fernanda Mara Coelho Pizani ${ }^{(a)}$, Ursula Ruchkys de Azevedo ${ }^{(b)}$, Fabiano Érico Vieira de. \\ Souza ${ }^{(\mathrm{c})}$ \\ (a) Departamento de Cartografia/Instituto de Geociências, Universidade Federal de Minas Gerais, \\ fm.coelho@yahoo.com.br \\ (b) Departamento de Cartografia/Instituto de Geociências, Universidade Federal de Minas Gerais, \\ tularuchkys@yahoo.com.br \\ (c) Departamento de Cartografia/Instituto de Geociências, Universidade Federal de Minas Gerais, \\ fabianoerico@hotmail.com
}

\section{Eixo: GEOTECNOLOGIAS E MODELAGEM ESPACIAL EM GEOGRAFIA FÍSICA}

\begin{abstract}
Resumo/
Os mapeamentos de vulnerabilidade vêm sendo desenvolvidos por meio de análise ambiental utilizando técnicas de geoprocessamento que permitem espacializar riscos auxiliando no planejamento urbano e na proposição de medidas preventivas. O presente trabalho faz um diagnóstico das áreas ambientalmente vulneráveis no município de Rio Acima utilizando geotecnologias. O método aplicado foi análise multicritério envolvendo os temas geologia, solo, uso e cobertura da terra, declividade e altimetria; cada classe de variável nos diferentes temas tiveram atribuídas notas em função da representatividade na questão da vulnerabilidade ambiental. Foi aplicada uma equação considerando a ponderação do resultado dos mapas temáticos resultando no mapa de vulnerabilidade ambiental do município de Rio Acima - MG. Os resultados indicam vastas áreas vulneráveis no município, associadas principalmente à presença de rochas suscetíveis ao deslizamento e grandes declividades. O resultado obtido pode auxiliar órgãos públicos e privados na elaboração de medidas de prevenção e no planejamento urbano.
\end{abstract}

Palavras chave: Geoprocessamento, Vulnerabilidade Ambiental, Análise Multicritério.

\section{Introdução}

A concepção de vulnerabilidade não é consenso entre os estudiosos e vem sendo utilizada em diferentes contextos. De maneira geral a vulnerabilidade está associada a susceptibilidade de uma área em relação aos efeitos negativos provenientes de determinadas ações. As características do meio físico e biótico interferem na vulnerabilidade podendo tornar os sistemas mais ou menos susceptíveis a determinados tipos de impactos.

De acordo com Crepani (2001), um mapeamento de vulnerabilidade deve levar em consideração dados sobre o meio físico, incluindo geologia, geomorfologia, solos, e dados decorrentes da altimetria, incluindo declividade e altimetria. Cada uma dessas variáveis têm determinado os índices de vulnerabilidade de acordo com o propósito da análise: 
"os parâmetros que se apresentam como indicadores de categoria morfodinâmica (como a espessura e maturidade do solo), ou aqueles capazes de influir decisivamente no desenvolvimento dos processos morfodinâmicos (como o grau de coesão das rochas, a densidade de cobertura vegetal, os índices morfométricos do terreno e a intensidade pluviométrica)".

Para este autor as áreas de maior vulnerabilidade são caracterizadas pela maior potencialidade de perda do solo o que pode acarretar movimento de massa levando ao transporte de tudo o que estiver acima do substrato afetado, incluindo residências, estradas, plantações, entre outros. Uma das formas utilizados para analisar a vulnerabilidade está associado ao uso de geotecnologias. Para Saito (2011) o uso de geotecnologias tem sido facilitado pelo acesso às ferramentas de geoprocessamento (como a constante difusão do uso do GPS, gratuidade de bons softwares de sistema de informação geográfica SIG -, disponibilidade livre de imagens de satélite) associada a estudos de mapeamento de monitoramento de desastres naturais. Por meio do uso de SIG’s é possível analisar áreas em diferentes datas, simular futuros cenários, avaliar ambientes por multicritérios, manipular dados, entre outras situações.

Crepani (1996; 2001) propõe uma metodologia de análise de áreas vulneráveis que resulta em mapas de vulnerabilidade ambiental direcionada ao desgaste do solo com o intuito de auxiliar no Zoneamento Ecológico-Econômico da Amazônia. Dessa forma, o autor reúne características do meio físico e gera escalas de vulnerabilidade das unidades mapeadas de acordo com os princípios da Ecodinâmica de Tricart (1977).

Neste contexto, o objetivo do artigo é mapear áreas de vulnerabilidade ambiental no município de Rio Acima, localizado na Região Metropolitana de Belo Horizonte (MG), considerando principalmente as características do meio físico do município utilizando técnicas de geoprocessamento.

\section{Caracterização da área de estudo}

A proximidade com a capital do Estado, Belo Horizonte, e sua inserção no Quadrilátero Ferrífero trazem uma pressão para o município relacionada a uma conjunção de fatores de ordem econômica, social e, sem dúvidas, ambiental. A Figura 1 indica a localização do município de Rio Acima em relação ao estado de Minas Gerais. 


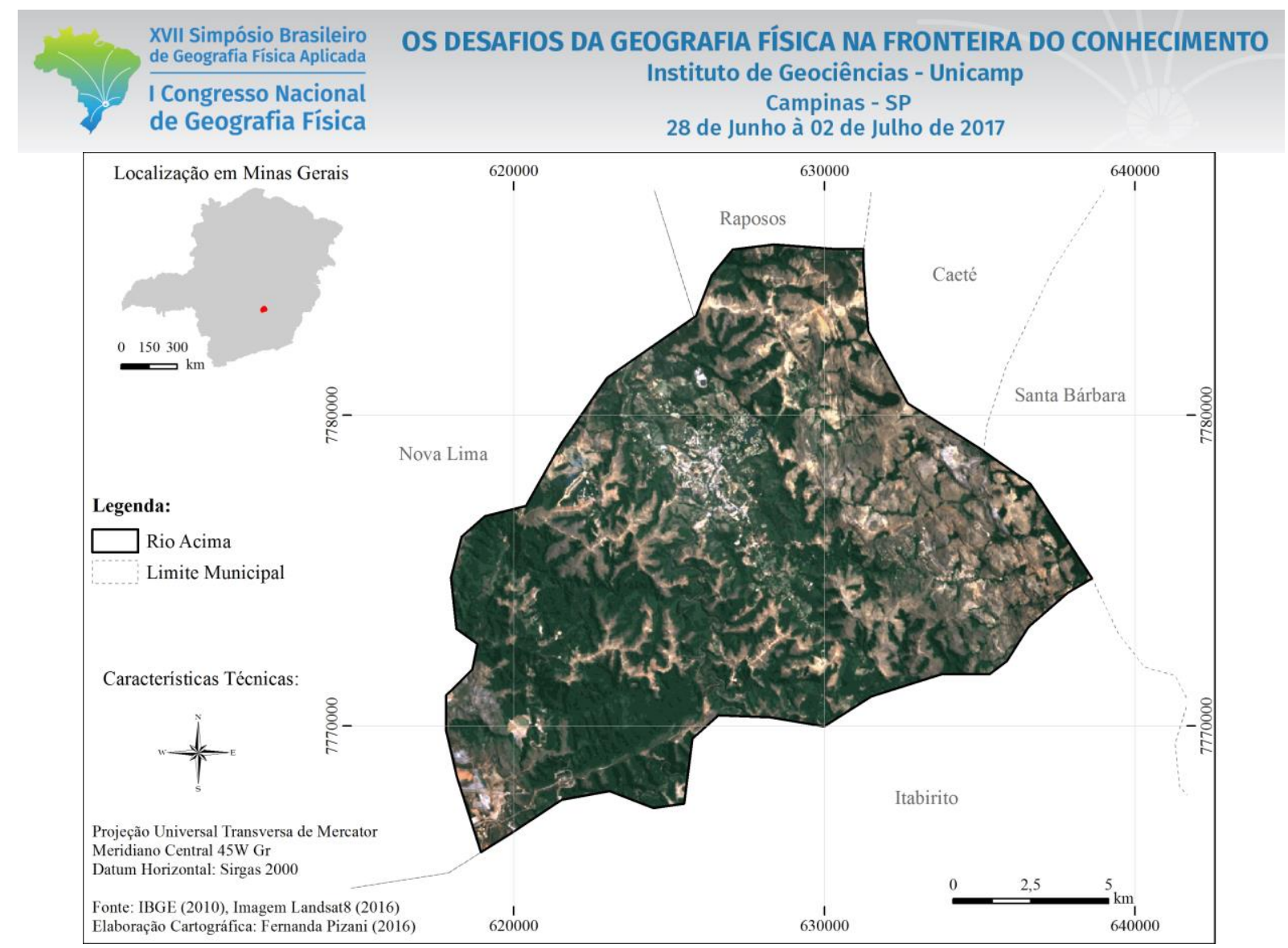

Figura 1 - Localização do município de Rio Acima/MG

O município de Rio Acima está inserido no contexto geológico do Quadrilátero Ferrífero que regionalmente é constituído por duas unidades litoestratigráficas arqueanas: complexos metamórficos e Supergrupo Rio das Velhas e por duas unidades Paleoproterozoicas: Supergrupo Minas e Grupo Itacolomi. Segundo Ruchkys et al. (2012) destaca-se ainda a presença de rochas básicas e metabásicas que cortam as unidades litoestratigráficas e o Fanerozoico encontra-se restrito a pequenas bacias intramontanas cenozóicas, como as bacias do Gandarela e do Fonseca.

No município afloram rochas do Supergrupo Rio das Velhas (porção central e leste) e do Supergrupo Minas (porção oeste). As rochas do Grupo Nova Lima (metavulcânicas) são predominantes na porção central e extremo leste do município enquanto as rochas do Grupo Maquiné (metassedimentares) ocorrem preferencialmente na porção leste.

O Supergrupo Minas ocorre na parte oeste do município com afloramentos dos Grupos Caraça, Itabira e Piracicaba. A análise do mapa geológico do município mostra ainda a ocorrência mais restrita de rochas do período Cenozóico, cujas unidades geológicas variam entre depósitos elúvios-coluviais, depósitos aluviais recentes e coberturas detrito-lateríticas. Também de forma restrita, datadas do Arqueano, ocorre exposição de rochas do embasamento cristalino do Complexo Bação.

O município está situado à Bacia do Rio São Francisco e é banhado pelo Rio das Velhas. Outros córregos de menor importância também servem ao local, como é o caso dos córregos do Vilela, da Água Limpa e Santo Antônio que, junto com outros mais, deságuam no São Francisco contra a 
correnteza gerando o fenômeno de águas correndo acima, o que caracteriza a denominação do local. As maiores altitudes são alcançadas na Serra Gandarela atingindo 1665 m.

\section{Materiais e métodos}

\subsection{Materiais utilizados}

Para a efetivação deste trabalho, foram utilizados os dados em formato vetorial de geologia e geomorfologia fornecidos pelo Relatório de Zoneamento Ecológico-Econômico - ZEE da APA Sul (datados de 2008, em escala 1:50000), limite de território municipal de Rio Acima fornecido pelo Instituto Brasileiro de Geografia e Estatística - IBGE (datados de 2010, em escala 1:50000) e imagem digital de elevação de terreno SRTM, para a extração de informações de declividade e altimetria, fornecida pelo Serviço Geológico dos Estados Unidos - USGS (datada de 2016, com resolução espacial de 30m).

\subsection{Métodos}

A Figura 2 exprime a estrutura geral do método utilizado para atingir os objetivos deste trabalho tendo como referência a proposta de Crepani (2001): 


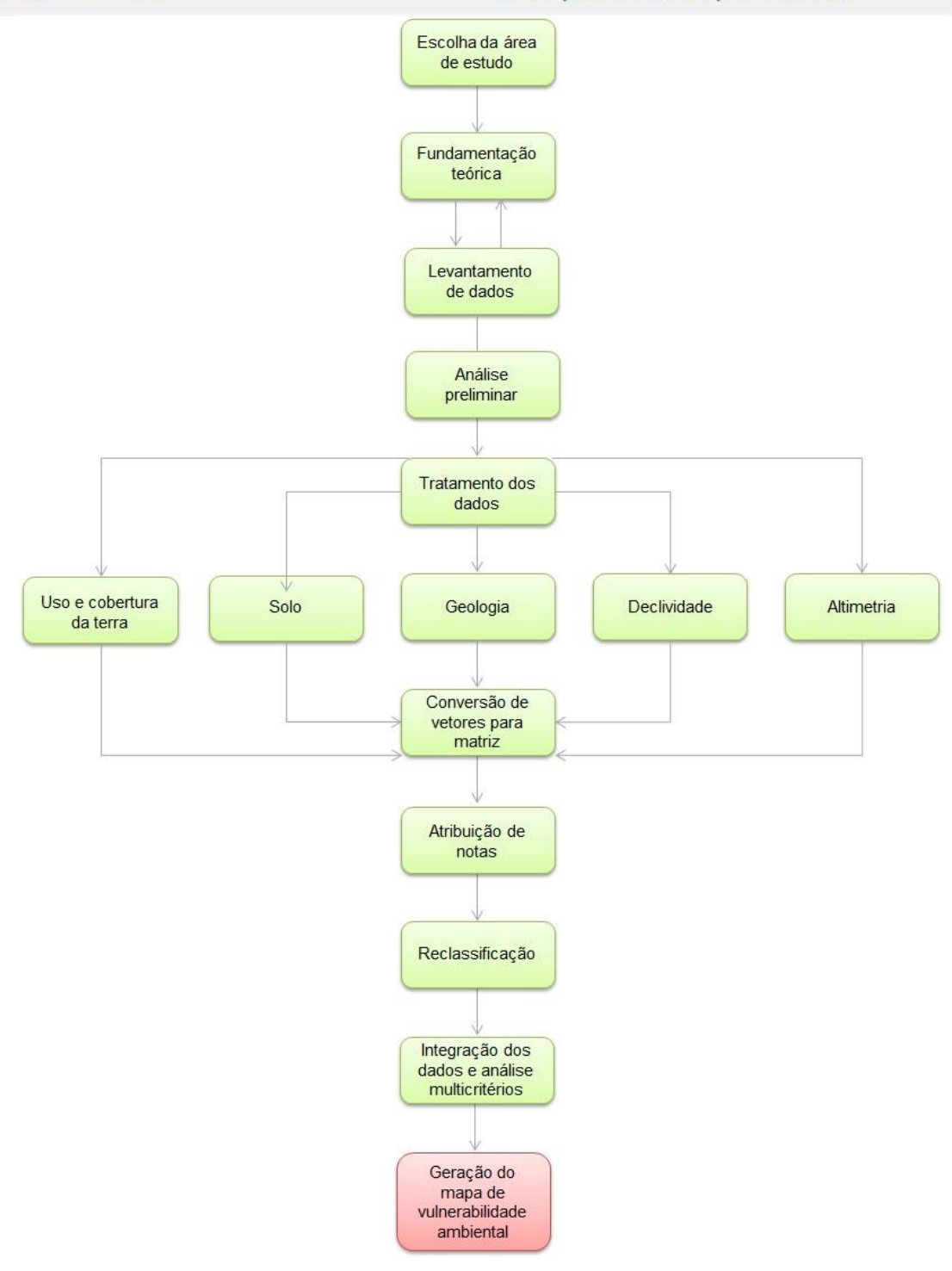

Figura 2 - Fluxograma das etapas metodológicas

Primeiramente os dados temáticos de geologia, solo, cobertura e uso da terra foram tratados e recortados em relação a área do município de Rio Acima. A partir da imagem SRTM foram gerados os mapas de hipsometria e de declividade (Figura 3). 

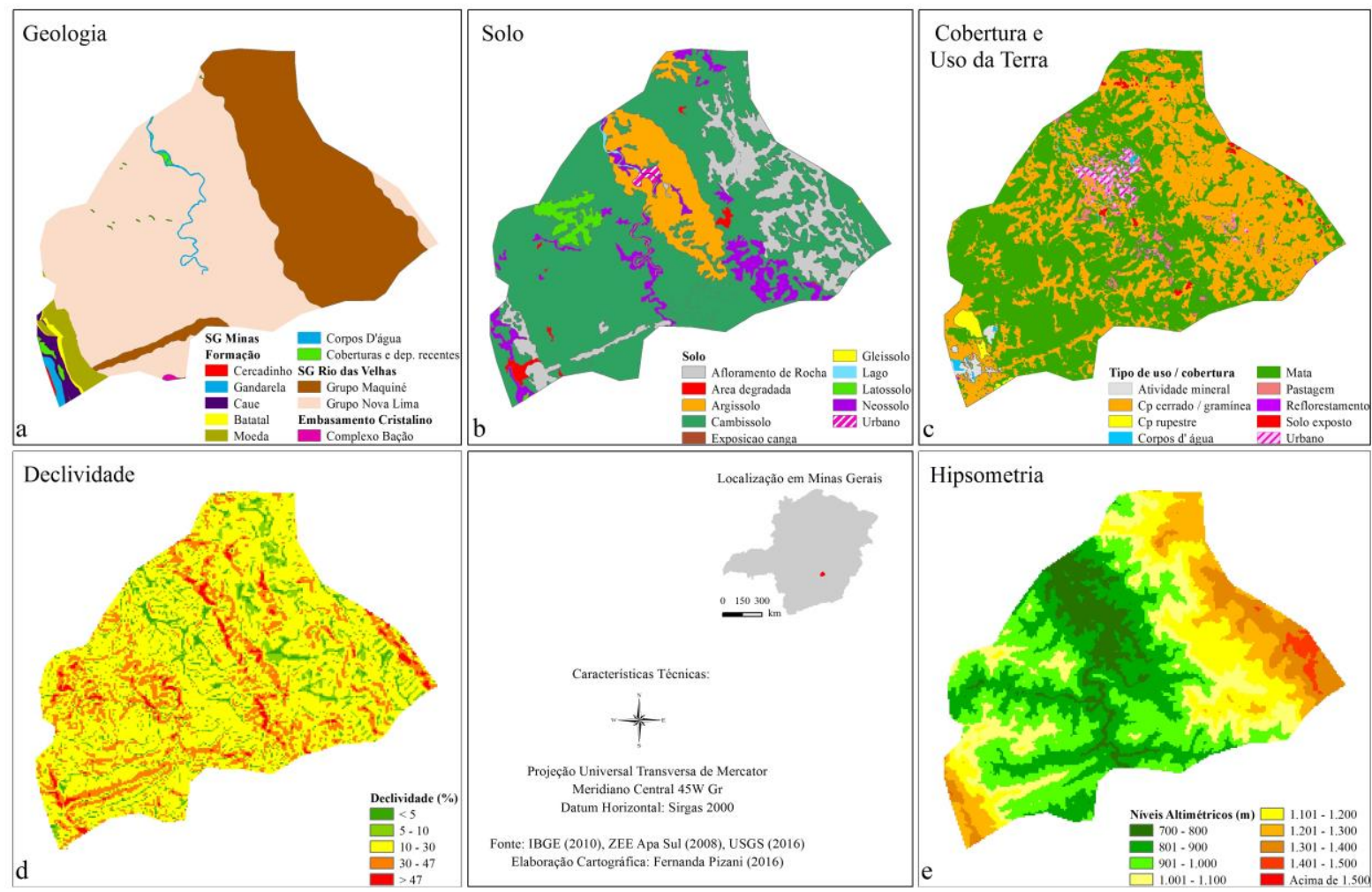

Figura 3 - Mapas das variáveis geologia (a), solo (b), cobertura e uso da terra (c), declividade (d) e hipsometria (e) do município de Rio Acima/MG

Para atribuição de notas das variáveis dentro de cada tema foram adaptados os critérios adotados por Crepani (2001) apresentados na Tabela III sendo que as notas poderiam variar de 1 a 5 , sendo atribuída a nota 1 para grau baixo de vulnerabilidade e 5 para alta vulnerabilidade (Tabela IV).

Tabela III - Critérios qualitativos adotados

Fonte: Adaptado de Crepani (2001)

\begin{tabular}{|c|c|}
\hline Tema & Critérios \\
\hline Geologia & Idade geológica e fragilidade \\
\hline Solo & Maturidade do solo \\
\hline Declividade & Variação da declividade \\
\hline Cobertura e uso da terra & Densidade de cobertura vegetal \\
\hline Altimetria & Variação da altitude \\
\hline
\end{tabular}

Tabela IV - Avaliação da vulnerabilidade ambiental

\begin{tabular}{|c|c|}
\hline Valor & Grau de vulnerabilidade \\
\hline 1 & Baixa \\
\hline 2 & Baixa a média \\
\hline 3 & Média \\
\hline
\end{tabular}




\begin{tabular}{|c|c|}
\hline 4 & Média a alta \\
\hline 5 & Alta \\
\hline
\end{tabular}

Para elaboração do mapa de vulnerabilidade, após a atribuição das notas para as variáveis de cada tema, fez-se a ponderação dos temas considerando sua importância relativa na área de estudo e realizou-se a análise multicritérios por meio de álgebra de mapas. A Tabela V apresenta os temais com suas respectivas variáveis e notas (valor de vulnerabilidade) e os pesos considerados para a vulnerabilidade ambiental do município de Rio Acima.

Tabela $\mathrm{V}$ - Notas e pesos atribuídos para os temas e suas variáveis

Fonte: Adaptado de Crepani (2001)

\begin{tabular}{|c|c|c|c|}
\hline Tema & Variável & Nota & Peso \\
\hline \multirow{11}{*}{ Geologia } & Cobertura Detrito-laterítica & 2 & \multirow{11}{*}{$35 \%$} \\
\hline & Depósito Aluvial recente & 2 & \\
\hline & Depósito Elúvio-coluvial & 2 & \\
\hline & Formação Cercadinho & 5 & \\
\hline & Formação Cauê & 3 & \\
\hline & Formação Gandarela & 4 & \\
\hline & Formação Moeda & 2 & \\
\hline & Formação Batatal & 5 & \\
\hline & Grupo Maquiné & 2 & \\
\hline & Grupo Nova Lima & 3 & \\
\hline & Complexo Bação & 1 & \\
\hline \multirow{9}{*}{ Solo } & Afloramento de Rocha & 5 & \multirow{9}{*}{$20 \%$} \\
\hline & Área degradada & 5 & \\
\hline & Argissolo & 2 & \\
\hline & Cambissolo & 4 & \\
\hline & Exposicao canga & 1 & \\
\hline & Gleissolo & 5 & \\
\hline & Latossolo & 1 & \\
\hline & Neossolo & 4 & \\
\hline & Urbano & 1 & \\
\hline \multirow{5}{*}{ Uso e cobertura } & Atividade mineral & 5 & \multirow{5}{*}{$15 \%$} \\
\hline & Campo cerrado / campo graminoso & 5 & \\
\hline & Campo rupestre & 5 & \\
\hline & Corpos d' agua & 5 & \\
\hline & Mata & 4 & \\
\hline
\end{tabular}




\begin{tabular}{|c|c|c|c|}
\hline & Pastagem & 5 & \\
\hline & Reflorestamento & 2 & \\
\hline & Solo exposto & 5 & \\
\hline & Urbano & 5 & \\
\hline \multirow{5}{*}{ Declividade } & $<3$ & 1 & \multirow{5}{*}{$15 \%$} \\
\hline & $3-7$ & 2 & \\
\hline & $7-15$ & 3 & \\
\hline & $15-30$ & 4 & \\
\hline & $>30$ & 5 & \\
\hline \multirow{5}{*}{ Altimetria } & $<900$ & 1 & \multirow{5}{*}{$15 \%$} \\
\hline & $900-1100$ & 2 & \\
\hline & $1100-1300$ & 3 & \\
\hline & $1300-1400$ & 4 & \\
\hline & $>1400$ & 5 & \\
\hline
\end{tabular}

Com a atribuição das notas para cada variável dos temas analisados foi aplicada a equação final e gerado o mapa de vulnerabilidade:

Vulnerabilidade $=$ geologia $* 0,35+$ solo $* 0,20+$ uso e cobertura $* 0,15+$ declividade $* 0,15+$ altimetria $* 0,15$

\section{Resultados e discussões}

Da aplicação da análise multicritério foi gerado o mapa de vulnerabilidade do município de Rio Acima (Figura 8). A relação entre o valor absoluto e o valor relativo para cada classe de vulnerabilidade encontrada no município é apresentada na tabela VI. 


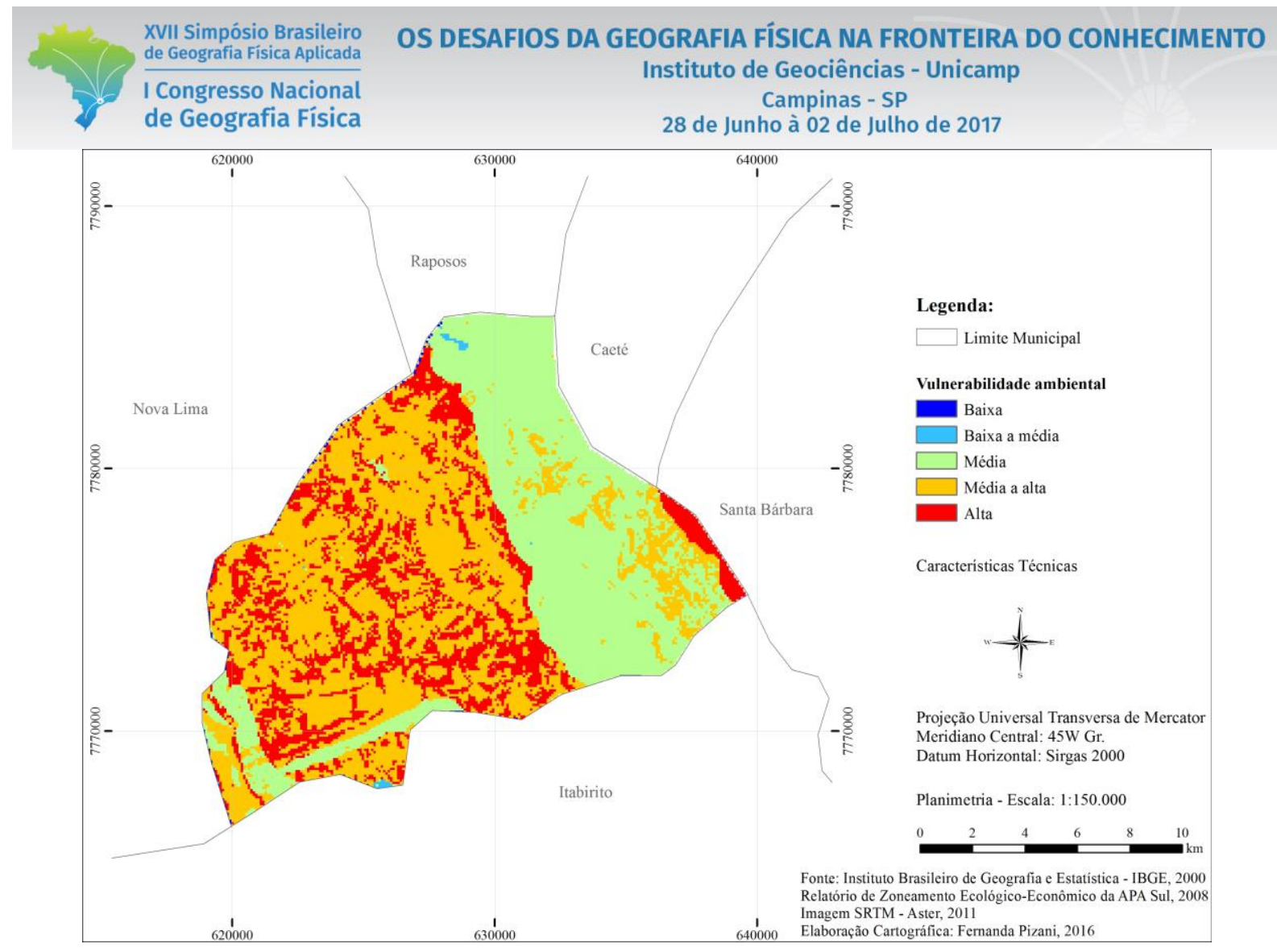

Figura 4 - Mapa de vulnerabilidade ambiental do Município de Rio Acima/MG

Tabela VI - Área correspondente às classes de vulnerabilidade ambiental

\begin{tabular}{|c|c|c|}
\hline Grau de vulnerabilidade & Valor absoluto $\left(\right.$ Área em $\left.\mathrm{km}^{2}\right)$ & Valor relativo (\%) \\
\hline Baixa & 1,02 & 0,46 \\
\hline Baixa a média & 0,45 & 0,20 \\
\hline Média & 74,17 & 33,33 \\
\hline Média a alta & 101,33 & 45,54 \\
\hline Alta & 45,55 & 20,47 \\
\hline Valor total & 222,52 & 100,00 \\
\hline
\end{tabular}

Observa-se em vermelho, na porção central do município, áreas com elevada suscetibilidade a deslizamentos. De certa forma esta ocorrência está associada à presença de xistos (Grupo Nova Lima) que, devido a sua composição, apresentam um comportamento plástico, deslizando facilmente quando em plano inclinado.

Outras áreas de maior vulnerabilidade correspondem aos elevados declives encontrados nas serras do Gandarela e Moeda. Nesta pequena porção da Serra do Gandarela (à extremo oeste do município) afloram rochas, igualmente, do Grupo Nova Lima que associadas à alta declividade resultaram em áreas altamente vulneráveis. Na Serra da Moeda, a fragilidade está associada à presença de xistos (Formação Cercadinho) e filitos (Formação Cercadinho e Batatal). Neste caso, mesmo que como outra 
associação litológica mais estável, como solo laterítico, fragmentos de itabirito, hematita (coberturas detrito-lateríticas e depósitos recentes) e itabirito (Formação Cauê) os elevados declives constituem-se em fatores determinantes do deslizamento.

As áreas de média vulnerabilidade são as áreas em tons de verde claro e correspondem àquelas onde há presença de quartzito, conglomerado (entre outras rochas menos frágeis), declividades medianas, solo mais vulnerável (como afloramento de rocha e cambissolo) que, quando associados, apresentam resultados intermediários.

O município apresenta raras porções de baixa vulnerabilidade, justificadas no mapa final em tons de azul. Esta ocorrência está combinada à presença de granito / gnaisse (Complexo Bação), baixíssimos níveis altimétricos e declividade, que se mostraram decisivos, uma vez que esta porção apresenta incidência de cambissolo e mata (fatores que favorecem a vulnerabilidade do ambiente).

\section{Considerações finais}

Acredita-se que o mapeamento da vulnerabilidade ambiental realizado para o município de Rio Acima possa contribuir na elaboração de medidas de prevenção já que proporciona a espacialização dos riscos com base na análise integrada de variáveis que interferem nos deslizamentos. Sendo assim, a identificação das situações de risco apresentadas neste trabalho pode vir a subsidiar órgãos públicos e privados no que diz respeito ao planejamento urbano e na proposição de medidas de prevenção.

Para a elaboração do mapa de vulnerabilidade ambiental, que indica as áreas propensas a riscos oriundos da perda de solos, utilizou-se a metodologia multicritério realizada com Sistemas de Informação Geográfica (SIG) que constitui um instrumento valioso para apoiar as mais diferentes atividades de planejamento, incluindo análise de suscetibilidade ao risco.

Embora o mapa final seja resultado de certa subjetividade inerente ao processo de abstração da realidade, buscou-se ponderar e atribuir notas as variáveis e seus elementos considerando a realidade da área estudada. Neste sentido, buscando melhorar o resultado obtido é importante a realização de trabalhos de campo a fim de verificar, nas áreas classificadas como de maior vulnerabilidade, as condições de ocupação e construções que podem potencializar os prejuízos decorrentes dos riscos naturais associados a áreas onde o substrato é mais plástico ou em ambiente íngreme.

Dessa forma, conforme o interesse e a necessidade, a pesquisa apresentada permite que novas variáveis sejam acrescidas de forma a enriquecer o resultado. 


\section{Bibliografia}

CAMPOS, L. C. Proposta de reanálise do risco geológico-geotécnico de escorregamentos em Belo Horizonte - Minas Gerais. Dissertação de mestrado, Escola de Engenharia, Universidade Federal de Minas Gerais. Belo Horizonte, 2011.

CARRIJO, M. G. G. Análise da vulnerabilidade ambiental: o caso do Parque Estadual das Nascentes do Rio Taquari-MG. Dissertação de mestrado, Centro de Ciências Exatas e Tecnologia, Universidade Federal do Mato Grosso do Sul. Campo Grande, 2005.

CREPANI, E.; Medeiros, J. S. de; Azevedo, L. G. DE.; Hernandez Filho, P.; Florenzano, T. G.; Duarte, V. Curso de sensoriamento remoto aplicado ao zoneamento ecológico-econômico. São José dos Campos: INPE, 2001.25p.

FIGUEIRÊDO, et al. Análise da vulnerabilidade ambiental. Fortaleza: Embrapa Agroindústria Tropical, 2010. 47p. ISSN 1677-1915, 127.

HOGAN, D. J. Mobilidade populacional, sustentabilidade ambiental e vulnerabilidade social. Rev. Bras. estud. popul., Dez 2005, vol.22, n.2, p.323-338. ISSN 0102-3098.

INSTITUTO BRASILEIRO DE GEOGRAFIA E ESTATÍSTICA. Cidades@: Minas Gerais. Disponível em: <http://www.ibge.gov.br/cidadesat/link.php?uf=mg>. Acesso em 09 nov. 2013.

LOBÃO, et al. Mapeamento das unidades ecodinâmicas: subsídio ao estudo da vulnerabilidade ambiental no polo de Irecê-BA. Revista Geonorte, Edição Especial, v.2, n.4, p. 1560-1573.

PARIZZI, M. G. et al. Processos de movimentos de massa em Belo Horizonte, MG. Geografias Online (UFMG), v. 12, p. 58-87, 2011.

RODRIGUES, F. S.; PEREIRA, J. G. Uso da geotecnologia na avaliação ambiental na zona de amortecimento do Parque Nacional da Serra da Bodoquena. Anais XVI Simpósio Brasileiro de Sensoriamento Remoto, Foz do Iguaçu, Brasil, 13-18 abril 2013, INPE, p. 4338-4345.

ROSÁRIO, G. O. Análise espacial aplicada à determinação do risco de erosão do solo na porção Noroeste do município de Itabirito. Monografia, Especialização em Geoprocessamento, Instituto de Geociências, Universidade Federal de Minas Gerais. Belo Horizonte, 2010.

SAITO, S. M. Desastres naturais e geotecnologias: vulnerabilidade. São José dos Campos: INPE, 2011. 35p.

SANTOS, C. A.; SOBREIRA, F. G. Análise da fragilidade e vulnerabilidade natural dos terrenos aos processos erosivos como base para o ordenamento territorial: o caso das bacias do Córrego Carioca, Córrego do Bação e Ribeirão Carioca na região do Alto Rio das Velhas-MG. Revista de Geomorfologia, v.9, n.1, p. 65-73, 2008.

SECRETARIA DO PLANEJAMENTO E MEIO AMBIENTE (SEPLAN). Vulnerabilidade de Paisagens à Perda de Solos da Folha SB.23-V-C. Diretoria de Zoneamento Ecológico-Econômico (DZE). Projeto de Gestão Ambiental Integrada da Região do Bico do Papagaio. Zoneamento Ecológico-Econômico. Imperatriz. Org. por Edson Crepani e Ricardo Ribeiro Dias. Palmas, Seplan/DZE, 2006. 48p.

SOUTO, M. V. S.; AMARO, V. E. Aplicação das técnicas de geoprocessamento para o mapeamento da vulnerabilidade natural para a região da Ponta do Tubarão, litoral setentrional do Estado do Rio Grande do Norte, município de Macau. XII Simpósio Brasileiro de Sensoriamento Remoto, Goiânia, Brasil, 16-21 abril 2005, INPE, p. 2773-2778. 